\title{
Comparison of serum protein profiles between major depressive disorder and bipolar disorder
}

Sang Jin Rhee ${ }^{1,2}$, Dohyun Han ${ }^{3}$, Yunna Lee ${ }^{1}$, Hyeyoung Kim ${ }^{1,4}$, Junhee Lee ${ }^{1}$, Kangeun Lee ${ }^{1}$, Hyunsuk Shin ${ }^{3}$, Hyeyoon Kim ${ }^{3,5}$, Tae Young Lee ${ }^{6,7}$, Minah Kim ${ }^{1,2}$, Se Hyun Kim ${ }^{1}$, Yong Min Ahn ${ }^{1,2,6}$, Jun Soo Kwon ${ }^{1,2,6}$ and Kyooseob $\mathrm{Ha}^{1,2,6^{*}}$

\begin{abstract}
Background: Major depressive disorder and bipolar disorder are prevalent and debilitating psychiatric disorders that are difficult to distinguish, as their diagnosis is based on behavioural observations and subjective symptoms. Quantitative protein profile analysis might help to objectively distinguish between these disorders and increase our understanding of their pathophysiology. Thus, this study was conducted to compare the peripheral protein profiles between the two disorders.

Methods: Serum samples were collected from 18 subjects with major depressive disorder and 15 subjects with bipolar disorder. After depleting abundant proteins, liquid chromatography-tandem mass spectrometry (LC-MS/MS) and label-free quantification were performed. Data-dependent acquisition data were statistically analysed from the samples of 15 subjects with major depressive disorder and 10 subjects with bipolar disorder who were psychotropic drug-free. Two-sided t-tests were performed for pairwise comparisons of proteomes to detect differentially-expressed proteins (DEPs). Ingenuity Pathway Analysis of canonical pathways, disease and functions, and protein networks based on these DEPs was further conducted.

Results: Fourteen DEPs were significant between subjects with major depressive disorder and those with bipolar disorder. Ras-related protein Rab-7a $\left(t=5.975, p=4.3 \times 10^{-6}\right)$ and Rho-associated protein kinase $2(\mathrm{t}=4.782, p=$ $\left.8.0 \times 10^{-5}\right)$ were significantly overexpressed in subjects with major depressive disorder and Exportin-7 $(\mathrm{t}=-4.520$, $p=1.5 \times 10^{-4}$ ) was significantly overexpressed in subjects with bipolar disorder after considering multiple comparisons. Bioinformatics analysis showed that cellular functions and inflammation/immune pathways were significantly different.

Conclusions: Ras-related protein Rab-7a, Rho-associated protein kinase 2, and Exportin-7 were identified as potential peripheral protein candidates to distinguish major depressive disorder and bipolar disorder. Further large sample studies with longitudinal designs and validation processes are warranted.
\end{abstract}

Keywords: Major depressive disorder, Bipolar disorder, Proteomics, rab7 protein, ROCK2 protein, human, XPO7 protein, human

\footnotetext{
* Correspondence: kyooha@snu.ac.kr

'Department of Neuropsychiatry, Seoul National University Hospital, Seoul, Republic of Korea

${ }^{2}$ Department of Psychiatry, Seoul National University College of Medicine, Seoul, Republic of Korea

Full list of author information is available at the end of the article
}

(C) The Author(s). 2020 Open Access This article is licensed under a Creative Commons Attribution 4.0 International License, which permits use, sharing, adaptation, distribution and reproduction in any medium or format, as long as you give appropriate credit to the original author(s) and the source, provide a link to the Creative Commons licence, and indicate if changes were made. The images or other third party material in this article are included in the article's Creative Commons licence, unless indicated otherwise in a credit line to the material. If material is not included in the article's Creative Commons licence and your intended use is not permitted by statutory regulation or exceeds the permitted use, you will need to obtain permission directly from the copyright holder. To view a copy of this licence, visit http://creativecommons.org/licenses/by/4.0/ The Creative Commons Public Domain Dedication waiver (http://creativecommons.org/publicdomain/zero/1.0/) applies to the data made available in this article, unless otherwise stated in a credit line to the data. 


\section{Background}

Major depressive disorder (MDD) and bipolar disorder (BD) are both prevalent psychiatric disorders with an overall prevalence of $3-10 \%$ and $2-4 \%$, respectively [1, 2]. Both disorders are debilitating, as MDD (unipolar depressive disorder) and bipolar affective disorder were ranked 1st and 4th among all mental and substance use disorders when calculating the Disability-Adjusted Life Year value in the Korean population [3]. Moreover, their associated mortality rates including death from suicide have significantly increased [4].

Distinguishing MDD from BD is challenging because diagnosis is mostly based on behavioural observations and subjective symptoms, and the conditions show similar manifestations. Although there is accumulating research regarding the differences between MDD and $\mathrm{BD}$ [5], more than $30 \%$ of subjects with BD are misdiagnosed initially with MDD [6], and the average lag time for correctly diagnosing $\mathrm{BD}$ after a diagnosis of MDD is nearly 10 years [7]. This might lead to mistreatment and antidepressant monotherapy prescription for subjects with BD [8], which worsens patient outcome by inducing hypomanic/manic or mixed states during the course of the disorder [9].

As the diagnosis of psychiatric disorders can be somewhat subjective, there has been growing efforts to discover objective biomarkers. Previous studies have involved large-scale genetic analyses followed by transcriptome evaluations $[10,11]$. Although these studies have shown some promising results, they also demonstrated the importance of focusing on -omics that are more reflective of the functions and phenotypes of an individual $[12,13]$. Traditionally, studies have focused on the central nervous system (post-mortem brain tissues and cerebrospinal fluid), but this is practically challenging in clinical practice because of invasiveness and accessibility issues $[13,14]$.

Thus, studies to quantitatively measure peripheral protein profiles that are associated with mood disorders have increased [12-14]. Analysing the protein profiles of $\mathrm{BD}$ and differentiating them from those of MDD, in particular, can increase the understanding of disease pathophysiology and help us to distinguish these disorders. Because of advances in analysis techniques, it is now possible to simultaneously measure numerous proteins in individual samples [12]. Different articles have reported quantitative protein profile differences between MDD or BD and controls [12, 15-18]. However, few studies have compared the profiles of MDD and BD [19, 20]. Thus, this study was conducted to compare the peripheral proteomic profiles between MDD and BD.

\section{Methods}

\section{Clinical samples}

Serum samples were initially collected from 18 subjects with MDD and 15 with BD (4 BD-I, 10 BD-II, and 1 BD
NOS), aged 16-42 years, from Seoul National University Hospital and Seoul National University Bundang Hospital between May 2012 and September 2017. Subjects were diagnosed clinically based on the DSM-IV or DSM-5 diagnosis for MDD and BD by psychiatric specialists. No subjects were diagnosed with substance-related (alcohol or drug use) disorders, and no subjects suffered from physical illnesses such as hypertension, endocrine diseases including diabetes or thyroid diseases, hypercholesteremia, liver diseases, or epilepsy. Those showing evidence of mental retardation or organic brain disease or with difficulty interpreting the Korean language were excluded. Demographic data were collected with written questionnaires, and symptom severity was assessed with the Hamilton depression rating scale [21]. Final statistical analysis was conducted for 25 subjects who had not been administered psychotropic drugs for at least 2 weeks and had no missing values for demographic and clinical data. At the time of blood collection, all subjects with MDD were in a mild-to-moderate depressive state and the clinical states of the subjects with BD were depressed $(N=5)$, depressive with irritability $(N=4)$, or hypomanic $(N=1)$.

Written informed consent was obtained from all individuals. Informed consent from both the individuals and parents/guardians was obtained for those under the age of 18. The study protocol was approved by the Institutional Review Board of Seoul National University Hospital (IRB No. 1704-075-846) and was conducted in accordance with the Declaration of Helsinki.

\section{Serum sample preparation}

Blood was collected in the morning after overnight fasting for at least $8 \mathrm{~h}$. Blood samples were centrifuged at 3000 $\mathrm{rpm}$ at $4{ }^{\circ} \mathrm{C}$ for $10 \mathrm{~min}$, and the serum was collected and stored at $<-70^{\circ} \mathrm{C}$. Serum samples were prepared according to the method reported by Geyer et al. (2016) [22] with some modifications. The protein digestion process was optimised to $2 \mu \mathrm{L}$ of each serum sample. Briefly, digestion buffer ( $8 \mathrm{M}$ urea, $5 \mathrm{mM}$ TCEP, $20 \mathrm{mM}$ CAA in $0.1 \mathrm{M} \mathrm{ABC}$ ) was added to the serum sample. The mixture was boiled for $25 \mathrm{~min}$ at $60^{\circ} \mathrm{C}$ to denature and alkylate the proteins. After cooling to room temperature, protein digestion was performed at $37^{\circ} \mathrm{C}$ overnight using a trypsin/ LysC mixture at a 100:1 protein-to-protease ratio. The second digestion was performed at $37^{\circ} \mathrm{C}$ for $2 \mathrm{~h}$ using trypsin (enzyme-to-substrate ratio $[\mathrm{w} / \mathrm{w}]$ of $1: 1000$ ). All resulting peptides were acidified with $10 \%$ trifluoroacetic acid and desalted using homemade C18-StageTips as described [23, 24]. Desalted samples were completely dried with a vacuum dryer and stored at $-80^{\circ} \mathrm{C}$.

\section{Establishment of a matching spectral library}

To construct a matching spectral library for matching between runs [25], a MARS-14 column (Agilent Technologies, 
Santa Clara, CA, USA) was used to remove the 14 blood proteins of highest abundance according to the manufacturer's instructions. The depleted samples were digested using the 2-step filter-aided sample preparation as described previously [23, 24]. Digested peptides were desalted using homemade C18-StageTips. For the in-depth data set, $25 \mu \mathrm{g}$ of purified peptides were fractionated using an Agilent 1260 bioinert HPLC (Agilent Technologies) equipped with an analytical column $(4.6 \times 250 \mathrm{~mm}, 5-\mu \mathrm{m}$ particle). High-pH reversed-phase peptide fractionation was performed at a flow rate of $0.8 \mathrm{~mL} / \mathrm{min}$ over a 60 -min gradient using solvent A (15 mm ammonium hydroxide in water) and solvent B (15 mM ammonium hydroxide in $90 \%$ acetonitrile). A total of 96 fractions was collected each minute and noncontiguously pooled into 24 fractions. The fractions were dried in a vacuum centrifuge and stored at $-80^{\circ} \mathrm{C}$ until liquid chromatography-tandem mass spectrometry (LC-MS/ MS) analysis.

\section{LC-MS/MS analysis}

LC-MS/MS analysis methods were performed using Quadrupole Orbitrap mass spectrometers, Q-exactive plus (Thermo Fisher Scientific, Waltham, MA, USA) coupled to an Ultimate 3000 RSLC systems (Dionex, Sunnyvale, CA, USA) with a nano electrospray source as previously described with some modifications $[23,26]$. Peptide samples were separated on the 2-column setup with a trap column $(75 \mu \mathrm{m}$ I.D. $\times 2 \mathrm{~cm}, \mathrm{C} 183 \mu \mathrm{m}, 100$ $\AA)$ and an analytical column $(50 \mu \mathrm{m}$ I.D. $\times 15 \mathrm{~cm}, \mathrm{C} 18$ $1.9 \mu \mathrm{m}, 100 \AA$ ). Prior to sample injection, the dried peptide samples were redissolved in solvent A ( $2 \%$ acetonitrile and $0.1 \%$ formic acid). After the samples were loaded onto the nano LC, a 90-min gradient from 8 to $30 \%$ solvent B ( $100 \%$ acetonitrile and $0.1 \%$ formic acid) was applied to all samples. The spray voltage was $2.0 \mathrm{kV}$ in positive ion mode and the temperature of the heated capillary was set to $320^{\circ} \mathrm{C}$. Mass spectra were acquired in data-dependent mode using a top 15 method on a Q Exactive. The Orbitrap analyser scanned precursor ions with a mass range of $300-1650 \mathrm{~m} / \mathrm{z}$ and resolution of 70 , 000 at $\mathrm{m} / \mathrm{z} 200$. Higher-energy collisional dissociation (HCD) scans were acquired on the Q Exactive at a resolution of 17,500. HCD peptide fragments were acquired at a normalised collision energy of 28 . The maximum ion injection times for the survey and MS/MS scans were 20 and $120 \mathrm{~ms}$, respectively.

\section{Data processing for label-free quantification}

MaxQuant (version 1.5.3.1) was used to process mass spectra [27], and the Andromeda engine was used to match MS/MS spectra with the Human Uniprot protein sequence database (December 2014, 88,657 entries) [28]. For total protein level analysis, primary searches were conducted using a 6-ppm precursor ion tolerance. The settings were as follows; MS/MS ion tolerance at 20 ppm, $\mathrm{N}$-Acetylation of proteins and oxidation of methionine as variable modifications, cysteine carbamidomethylation as fixed modification, and enzyme specificity to full tryptic digestion [26]. Peptides with a minimal length of six amino acids, and up to two missed cleavages were considered, and the false discovery rate (FDR) was set to $1 \%$ at peptide, protein, and modification levels [26]. To maximize quantification events across samples, matching between runs was performed using the depleted sample as a library.

\section{Statistical analysis}

Among the 33 subjects, 25 were free of psychotropic drugs for at least 2 weeks and had no missing values for demographic and clinical data. Data-dependent acquisition (DDA) data were statistically analysed in these subjects to enable comparisons of demographic and clinical characteristics between the two diagnostic groups and analyse the proteomic profiles independently of the effects of psychotropic drugs. Demographic and clinical differences between the diagnostic groups were analysed using a Mann-Whitney U-test for continuous variables and Fisher's exact test for dichotomous variables.

Statistical analyses for the DDA data were performed using Perseus software [29]. Initially, proteins identified as only identified by site, reverse, and contaminants were removed. The expression level of proteins in the serum was estimated by determining their Intensity Based Absolute Quantification (iBAQ) values calculated using Maxquant software. Because of the skewed distribution of the data, $\log _{2}$ transformation was conducted for these values. Valid values were filtered with proteins with a minimum of $70 \%$ quantified values in at least one diagnostic group. Missing values of the proteins were imputed based on a normal distribution (width $=0.3$, down-shift $=1.8$ ) to simulate signals of low-abundance proteins. Two-sided $t$-tests were performed for pairwise comparisons of proteomes to detect differentiallyexpressed proteins (DEPs). The protein abundances were subjected to z-normalisation followed by hierarchical clustering with Pearson's correlation distance.

Canonical pathways, diseases and functions, and protein networks were evaluated by Ingenuity Pathway Analysis (IPA, QIAGEN, Hilden, Germany) [30] based on the annotated DEPs with matched gene names. The analytical algorithms embedded in Ingenuity Pathway Analysis uses lists of DEPs to predict biological processes and pathways. Additionally, a tree-map was visualised, in which the major boxes represented categories of related biological functions or diseases. Statistical significance of both the gene ontology classification and enrichment analysis was determined by the Fisher's exact test. All 
Table 1 Demographic and clinical characteristics of the study subjects

\begin{tabular}{|c|c|c|c|c|}
\hline Characteristics & $\begin{array}{l}\text { Major depressive } \\
\text { disorder }(n=15)\end{array}$ & $\begin{array}{l}\text { Bipolar disorder } \\
(n=10)\end{array}$ & Statistics & $p$-value \\
\hline Age, mean $\pm S D$, years & $28.53 \pm 8.04$ & $25.10 \pm 4.91$ & $Z=-1.059$ & 0.29 \\
\hline $\mathrm{BMl}$, mean $\pm \mathrm{SD}, \mathrm{kg} / \mathrm{m}^{2}$ & $22.42 \pm 5.18$ & $22.41 \pm 5.17$ & $Z=-0.055$ & 0.96 \\
\hline $\mathrm{HAMD}$, mean $\pm \mathrm{SD}$ & $15.33 \pm 4.61$ & $12.10 \pm 3.54$ & $Z=-2.320$ & 0.02 \\
\hline Sex (Female), $n(\%)$ & $10(66.7 \%)$ & $7(70.0 \%)$ & Fisher's exact test & $>0.99$ \\
\hline Current smoker, $n$ (\%) & $1(6.7 \%)$ & $3(30.0 \%)$ & Fisher's exact test & 0.27 \\
\hline Duration from onset, mean $\pm S D$, years & $3.73 \pm 4.57$ & $4.80 \pm 2.94$ & $Z=-1.654$ & 0.10 \\
\hline Duration from the first psychotropic treatment, mean $\pm S D$, years & $0.33 \pm 0.49$ & $1.90 \pm 3.28$ & $Z=-0.974$ & 0.33 \\
\hline
\end{tabular}

Abbreviations: $S D$ standard distribution, $B M I$ body mass index, HAMD Hamilton depression rating scale

statistical tests were two-sided and $p<0.05$ was considered statistically significant.

\section{Results}

\section{Demographic and clinical characteristics}

In total, 15 subjects with MDD and 10 subjects with BD were included in the final statistical analysis of the DDA data. There were no significant differences between diagnostic groups regarding age, sex, body mass index, smoking, duration from onset, and duration from the first psychotropic treatment. Depressive symptoms were more severe in the MDD group (HAMD score; $15.33 \pm$ 4.61 vs $12.10 \pm 3.54, p=0.02$ ). A summary of the characteristics is presented in Table 1 .

\section{Quantitative analysis}

First, we performed comprehensive serum profiling using pooled serum samples with the depletion of 14 highly-abundant proteins to generate a peptide matching library, which consisted of 1616 proteins and 16,505 peptides. Thirty-three serum samples were analysed by unbiased single-shot approaches and "match between run" functionality with the constructed peptide library.
We quantified 481 serum proteins with at least two peptides. After considering proteins that were quantified by at least $70 \%$ in either the MDD group or BD group from drug-free patients, 268 proteins were subjected to statistical analysis (Additional file 1).

Two-sample $t$-tests showed that the levels of 14 proteins were significantly different between MDD and BD (Fig. 1). When adjusting for multiple comparisons using the Benjamini-Hochberg FDR adjusted $p$-value, the levels of Ras-related protein Rab-7a (RAB7A), Rhoassociated protein kinase 2 (ROCK2), and Exportin-7 (XPO7) were still significantly different (Table 2 and Additional file 2). Hierarchical clustering revealed that the two disorders generally clustered together (Fig. 2).

\section{Bioinformatics analysis}

The 14 proteins that were differentially expressed were subjected to bioinformatics analysis. The top five significant canonical pathways were LXR/RXR Activation (CD14, SAA4), IL-12 Signalling and Production in Macrophages (RAB7A, SAA4), Clathrin-mediated Endocytosis Signalling (RAB7A, SAA4), Actin Cytoskeleton Signalling (ROCK2, CD14), and the Extrinsic Prothrombin Activation Pathway

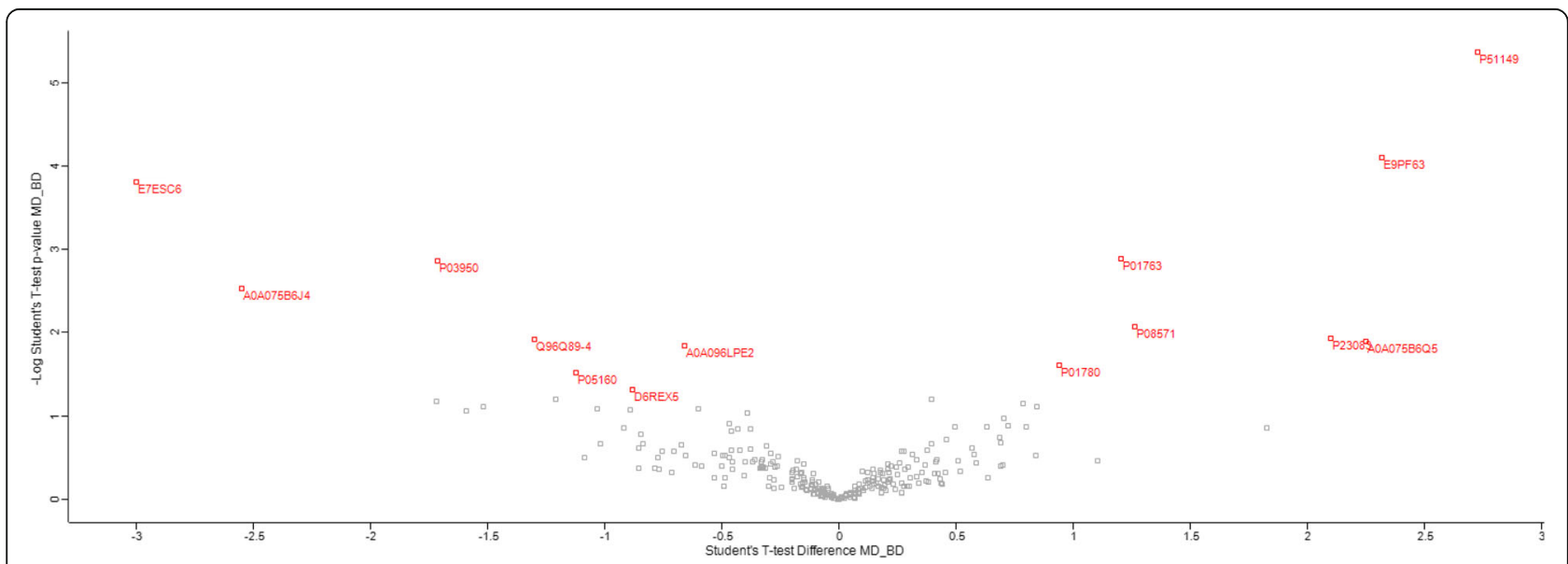

Fig. 1 Volcano plot of $p$-values for differentially-expressed proteins between major depressive disorder and bipolar disorder. Representative protein IDs in red indicate statistically significant differentially-expressed proteins based on a $p$ value $<0.05$ 
Table 2 Differentially expressed proteins between major depressive disorder and bipolar disorder

\begin{tabular}{|c|c|c|c|c|c|}
\hline Majority protein IDs & Protein names & Gene names & Fold change $^{a}$ & $\begin{array}{l}\text { Student's t-test } \\
\text { statistics }(\mathrm{t})\end{array}$ & $p$-value ${ }^{b}$ \\
\hline \multicolumn{6}{|l|}{ Overexpressed in MDD } \\
\hline P51149;C9J592;C9J8S3 & Ras-related protein Rab-7a & $R A B 7 A$ & 2.729 & 5.975 & $4.3 * 10^{-6}$ \\
\hline E9PF63;075116 & Rho-associated protein kinase 2 & ROCK2 & 2.321 & 4.782 & $8.0 * 10^{-5}$ \\
\hline P01763 & Ig heavy chain V-III region WEA & IGHV3-48 & 1.205 & 3.668 & 0.001 \\
\hline P08571;D6RFL4 & $\begin{array}{l}\text { Monocyte differentiation antigen } \\
\text { CD14;Monocyte differentiation } \\
\text { antigen CD14, urinary form; } \\
\text { Monocyte differentiation antigen } \\
\text { CD14, membrane-bound form }\end{array}$ & CD14 & 1.266 & 2.875 & 0.009 \\
\hline P23083 & Ig heavy chain V-I region V35 & IGHV10R15-1 & 2.103 & 2.739 & 0.011 \\
\hline A0A075B6Q5 & Ig heavy variable 3-64 & IGHV3-64 & 2.252 & 2.698 & 0.013 \\
\hline P01780 & Ig heavy chain V-III region JON & IGHV3-7 & 0.941 & 2.404 & 0.025 \\
\hline \multicolumn{6}{|l|}{ Overexpressed in BD } \\
\hline E7ESC6;Q9UIA9 & Exportin-7 & XPO7 & -2.999 & -4.520 & $1.5 * 10^{-4}$ \\
\hline P03950 & Angiogenin & ANG & -1.714 & -3.636 & 0.001 \\
\hline A0A075B6J4 & Ig lambda variable 3-25 & IGLV3-25 & -2.550 & -3.326 & 0.003 \\
\hline Q96Q89-4;Q96Q89-3;Q96Q89;Q96Q89-2 & Kinesin-like protein KIF20B & KIF2OB & -1.298 & -2.718 & 0.012 \\
\hline A0A096LPE2;P35542;A0A087X0E2 & $\begin{array}{l}\text { Serum amyloid A-4 protein; } \\
\text { Serum amyloid A protein }\end{array}$ & SAA2-SAA4;SAA4 & -0.660 & -2.640 & 0.015 \\
\hline P05160 & Coagulation factor XIII B chain & $F 13 B$ & -1.120 & -2.315 & 0.030 \\
\hline D6REX5;P49908;D6RIS9 & Selenoprotein P & SEPP1;SELENOP & -0.881 & -2.088 & 0.048 \\
\hline
\end{tabular}

Abbreviations: $M D D$ major depressive disorder, $B D$ bipolar disorder

${ }^{a}$ Fold change calculated by the difference of the logarithmic ${ }_{(2)}$ transferred intensity

${ }^{b}$ Boldface $p$-values are significant when adjusting for multiple comparison by using the Benjamini-Hochberg FDR adjusted $p$-value

(F13B). RAB7A was also included in the Remodeling of epithelial adherens junction pathway, and ROCK2 was included in the following pathways, Semaphorin Signalling in Neuron, PCP pathway, Actin Nucleation by ARP-WASP Complex, Ephrin A Signalling, Ephrin B Signalling, and Chemokine Signalling (Fig. 3 and Additional File 3).

The tree-map for diseases and functions is shown in Fig. 4. The DEPs were particularly enriched in organismal injury and abnormalities, cell-to cell signalling and interaction, cellular function and maintenance, inflammatory response, cellular assembly and organization, and neurological disease. (Additional File 3). Finally, network analysis of 14 DEPs in the serum of MDD samples versus $\mathrm{BD}$ were assessed. The first network consisted of six proteins (RAB7A, ROCK2, CD14, ANG, SELENOP, and KIF20B), and its related diseases and functions incorporated cellular movement, haematological system development and function, and immune cell trafficking (Fig. 5).

\section{Discussion}

In this study, we detected 14 DEPs between psychotropic drug-free MDD and BD subjects. RAB7A and ROCK2 were significantly overexpressed in MDD and XPO7 was significantly overexpressed in $\mathrm{BD}$ even after multiple comparisons. Bioinformatics analysis showed that cellular functions and inflammation/immune response pathways were significantly different.

To date, there are two published articles directly comparing DEPs between MDD and BD [19, 20]. Chen et al. (2015) compared plasma samples from drug-naïve patients and identified 25 DEPs, whereas Ren et al. (2017) compared plasma samples from drug-free patients and identified nine DEPs $[19,20]$. However, no proteins were common between studies [19, 20]. We compared serum samples from subjects with MDD and BD and found only one protein, Rho-associated protein kinase 2 (ROCK2), as a duplicate protein from the previous studies [20]. These discrepancies are likely related to variations in the study designs and differences in the demographic and clinical characteristics of the study. Our study was based on serum samples, and there is evidence that expression between the serum and plasma profiles can differ for certain proteins [18], which might explain these discrepancies. Moreover, the overall depressive symptoms were milder in our study, which might have also led to differences in the peripheral profiles.

The most significant DEP based on the fold-change and $p$-value was RAB7A, which was overexpressed in MDD compared to levels in BD. This protein is a key 

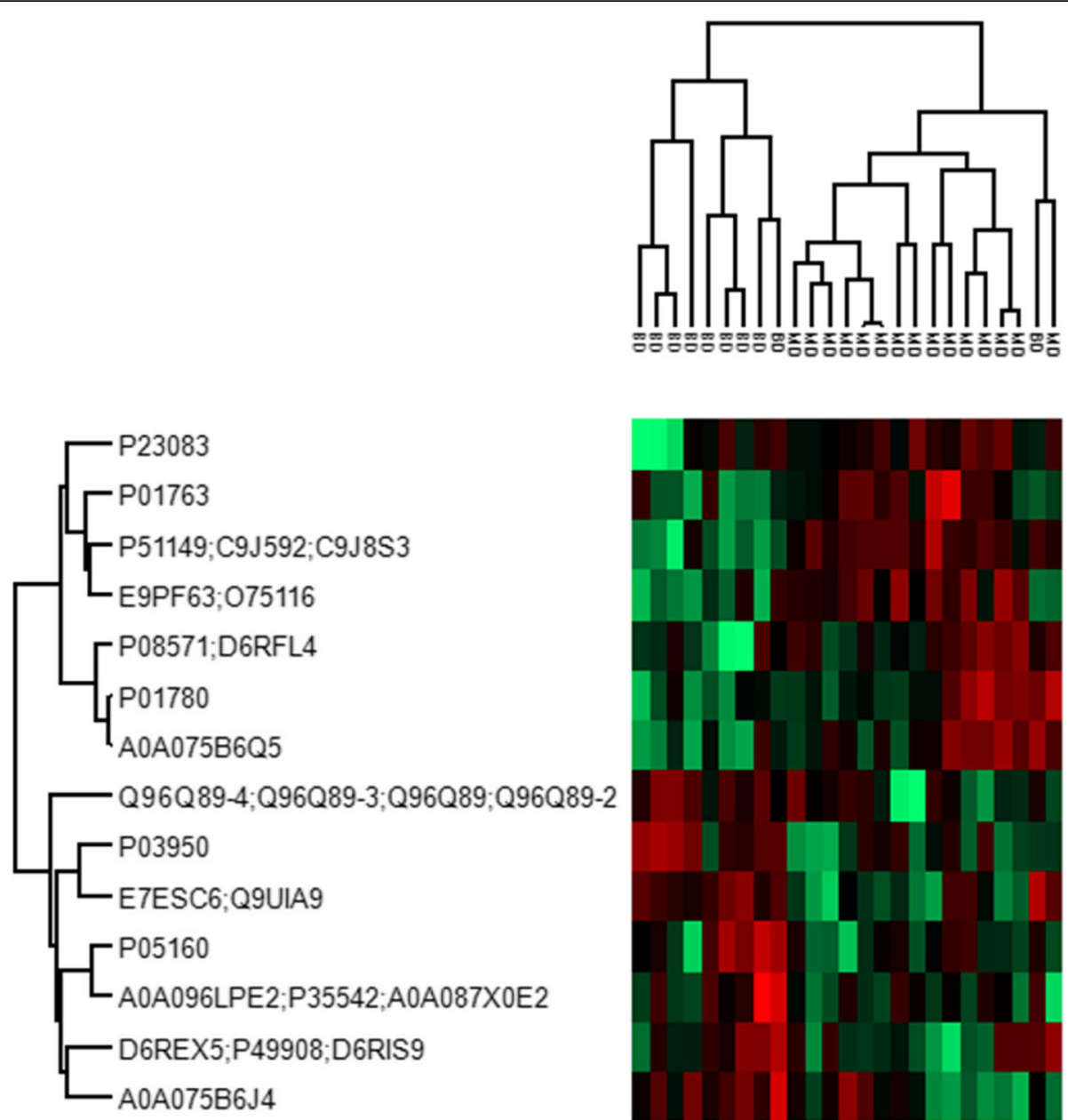

Fig. 2 Hierarchical clustering of statistically significant differentially-expressed proteins

regulator of endo-lysosomal trafficking [31] and is distributed in various components of the body including the central nervous system and peripheral blood [32, 33]. The level of RAB7A was increased in the cerebrospinal fluid of subjects with Alzheimer disease [33], and a recent study demonstrated that RAB7A gene expression was significantly changed in both the hippocampus and peripheral blood of subjects with Alzheimer disease, suggesting the possibility of screening Alzheimer disease from the peripheral blood [32]. However, its association with mood disorders is not well-understood. A previous study showed that RAB7A gene expression in the postmortem brain was up-regulated in patients with depression who died by suicide [34]. Recently, RAB7A was demonstrated to modulate endoplasmic reticulum stress [35], which is associated with mood disorders [36, 37]. Other functions of RAB7A include growth-factormediated cell signalling and lipid metabolism [38], which are also proposed mechanisms involved in the pathophysiology of mood disorders [39, 40]. Further studies focusing on the association between RAB7A and the different manifestations of mood disorders based on these functions are needed.

ROCK2 was also overexpressed in MDD compared to in $\mathrm{BD}$. The direction of expression and the protein itself were consistent with the results found by Chen et al. [20]. ROCK is a serine/threonine kinase that is a crucial regulator of the actin cytoskeleton and cell polarity [41]. It has two highly homologous isoforms, ROCK1 and ROCK2; interestingly ROCK2 is distributed mostly in the brain, spinal cord, and heart [42]. Inhibition of ROCK increases neurite outgrowth and axonal regeneration and activates pro-survival protein kinase $B$ in the central nervous system, and its potential for treating neurodegenerative diseases is being explored [41]. Direct associations considering the expression of ROCK2 and mood disorders are limited; one report showed that placental ROCK2 is down-regulated in women with depression [43]. However, there is evidence that ROCK2 expression increases during sleep deprivation [44] and ROCK2 is involved in the circadian variation of vascular contractility [45]. There is increasing evidence of the 


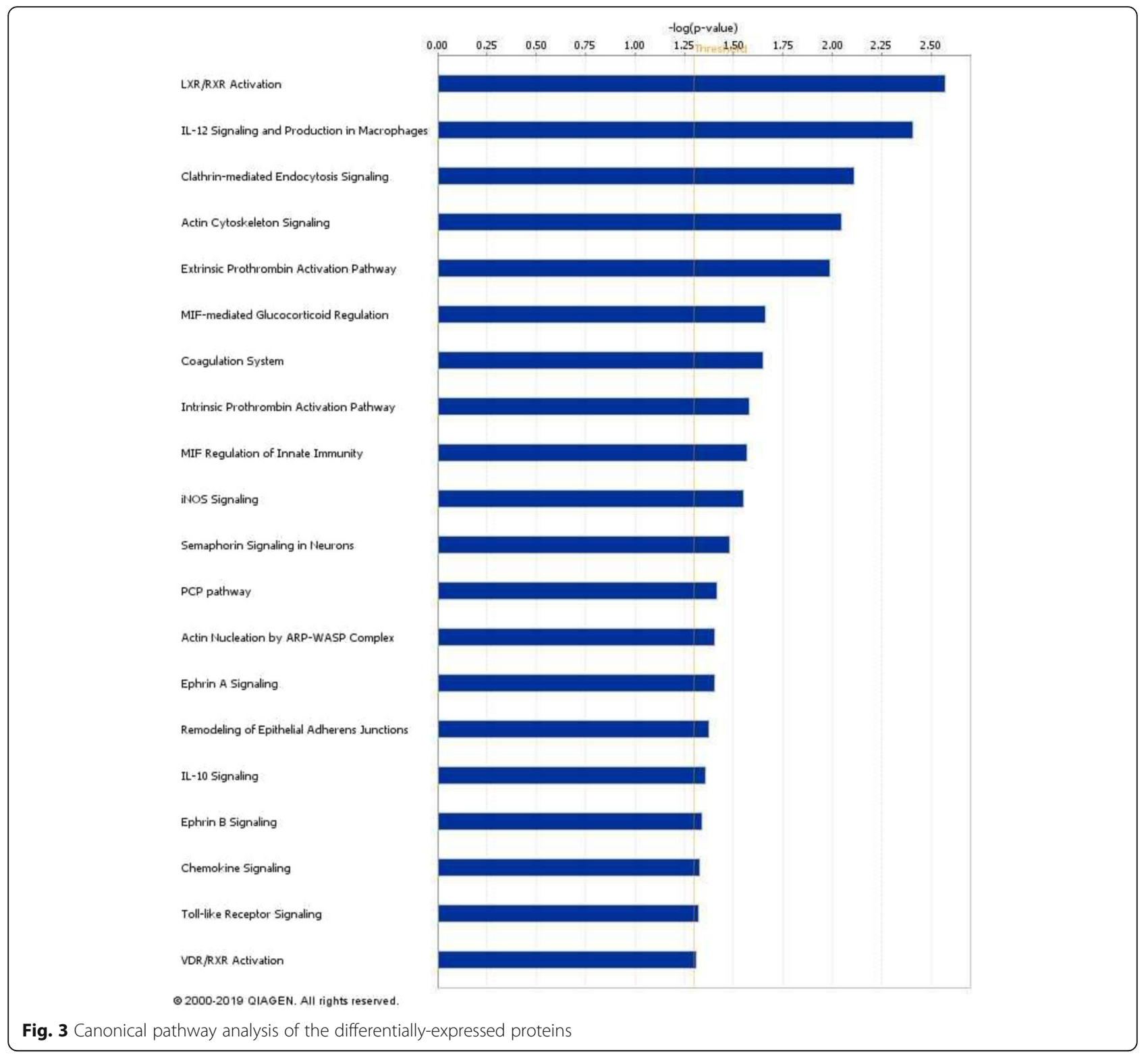

differences in sleep abnormalities and circadian rhythm dysregulation between MDD and BD, and circadian rhythm dysregulation has also been proposed as a marker specific for BD compared to MDD [46]. ROCK2 might also help to distinguish MDD from BD; studies of its role in circadian rhythm and mood dysregulation are needed.

$\mathrm{XPO} 7$ mediates the nuclear export of proteins with broad substrate specificity and was identified as one of the significant genes in a genome-wide association study on alcohol dependence $[47,48]$. In a confirmation study, this gene was significantly changed in patients with $\mathrm{BD}$ with comorbid alcohol dependence, but not in those without alcohol dependence [49]. However, its mechanism in alcohol dependence or mood disorders is unclear because of the lack of current literature linking XPO7 function with psychiatric manifestations.

Bioinformatics analysis revealed that cellular functions and inflammation/immune pathways are significantly altered. The most significant canonical pathway was found to be LXR/RXR (liver X receptor/retinoic acid receptor) activation. LXRs form heterodimers with RXRs, which regulate the expression of genes controlling sterol/fatty acid metabolism/homeostasis [50]. Interestingly, this pathway was recently demonstrated to be significantly altered in plasma DEPs in a mouse model of depression [51]. Inflammation and immune pathways were also significantly different, and these have been proposed to be involved in mood disorders [52-54]. Analysing the differences in protein expression associated with certain 


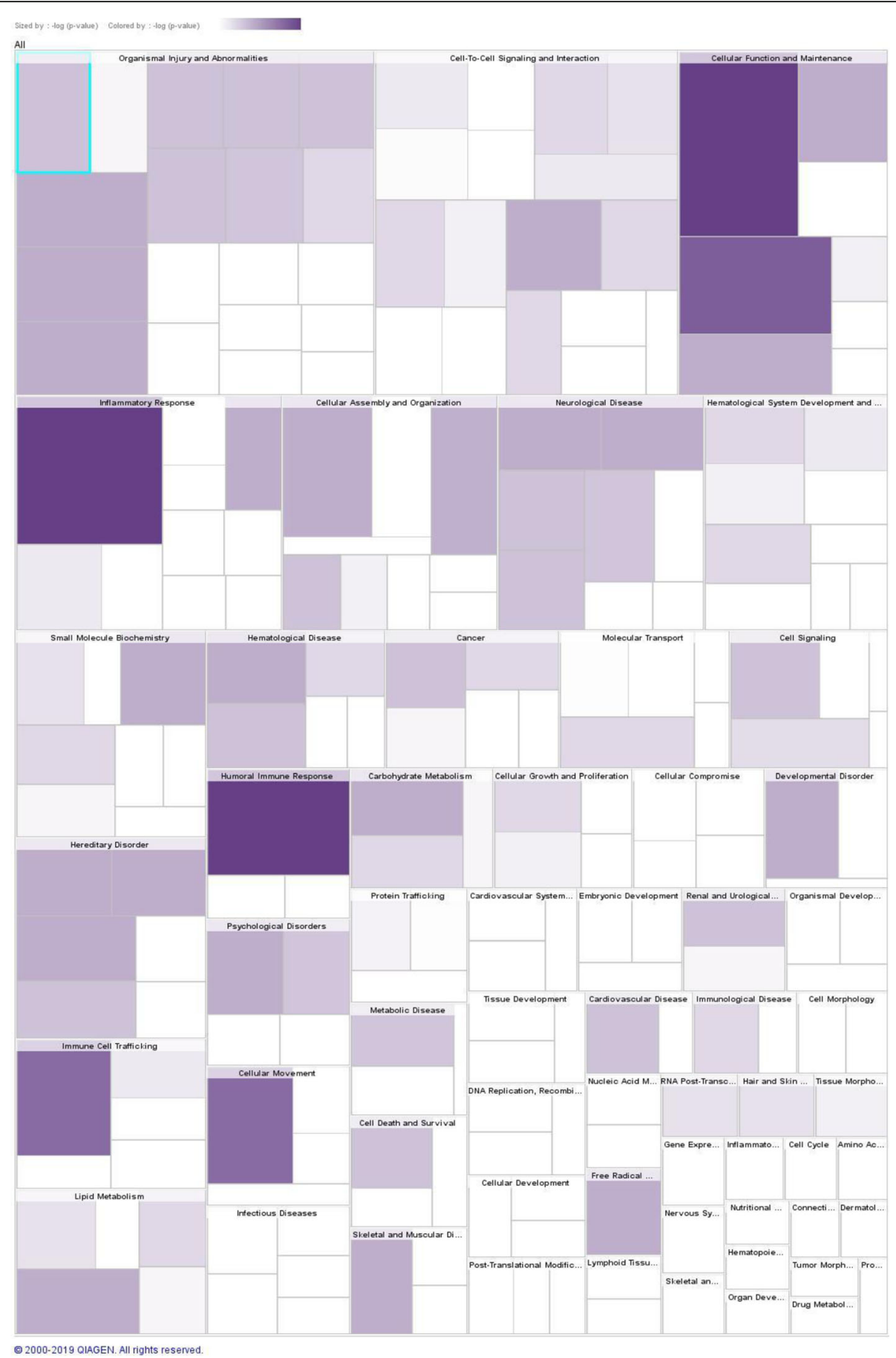

Fig. 4 Tree-map for diseases and functions of the differentially-expressed proteins. Major boxes represent categories of biological functions/ diseases and individual rectangles represent an individual biological function or disease. The size of a rectangle is correlated with increasing overlap significance and darker colours indicate lower p-values

biological pathways, and mood disorder subtypes might improve our ability to differentiate BD from MDD.

The present study had several limitations. First, the sample size was small, and the study lacked a control group without mental disorders. Larger sample sizes would increase the power to detect DEPs, which might improve the precision of bioinformatics analysis. The lack of a control group made it difficult to interpret the direction of overexpression of proteins between the disorders. Second, this was a cross-sectional study, and thus a causal relationship between the protein profiles and disorders could not be determined. Moreover, in cross- 


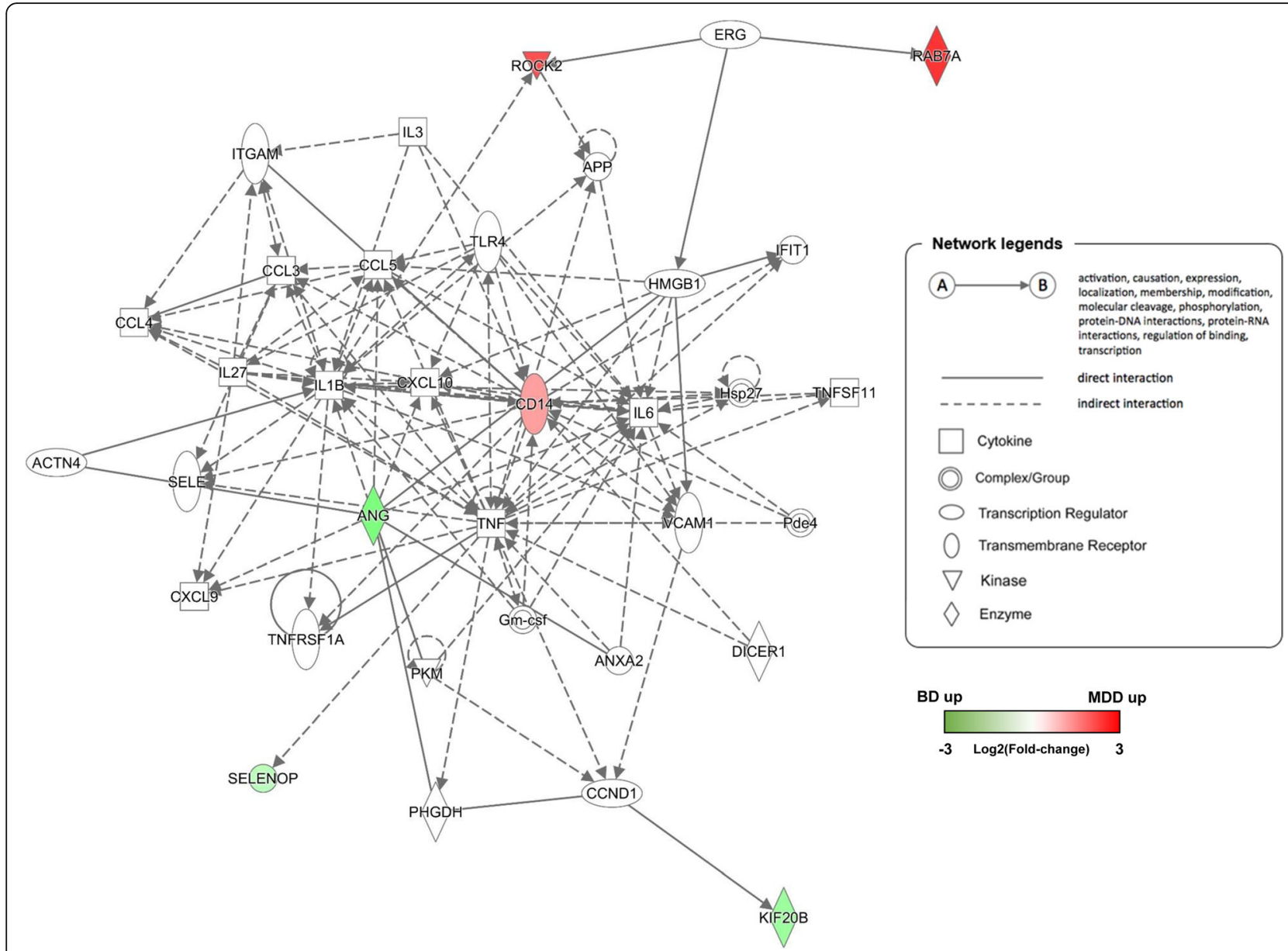

Fig. 5 Top protein network generated by IPA for 14 differentially-expressed serum proteins in MDD versus BD. Direct and indirect interactions are represented by the solid and dashed lines, respectively. The shapes represent the molecular classes of the proteins defined in the legend. The protein interaction networks were generated through the use of IPA. MDD, major depressive disorder; BP, bipolar disorder; IPA, Ingenuity

Pathway Analysis

sectional designs, the diagnosis of MDD always has the potential to be associated with undiscovered BD because of hypomanic/manic episodes that have not yet manifested or patient non-reporting. Third, our study lacked validation. Validation in a different group based on enzyme-linked immunosorbent assay would reveal the reliability of our results. However we were not able to confirm the results with alternative assays because of the insufficiency of residual samples. Fourth, as depressive symptoms were more severe in the MDD group, there are possibilities that such differences in depression severity could have influenced the main findings of the study. However, of note, the association between levels of the three major DEPs and diagnosis (MDD or BD) was still significant after additionally controlling for the total HAMD score as a covariate in linear regression models. Fifth, treatment histories could have influenced the results. Even though we only analysed those who were drug-free, treatment regimens and the total duration of treatment before the drug-free period could have influenced the results. Finally, other uncontrolled covariates such as exercise might have influenced the protein profiles. However, despite these limitations, our study's strength is that we focused on the difference between MDD and BD, which is an understudied subject, and detected potential DEPs. Additionally, we only recruited drug-free subjects and performed sampling in the morning after overnight fasting, which contributed to the control of factors that affect protein expression.

\section{Conclusions}

In conclusion, the present study demonstrated that serum proteomic profiles differed between MDD and BD. RAB7A, ROCK2, and XPO7 proteins were significantly changed after controlling for multiple comparisons. These proteins might enable differential diagnosis and expand our understanding of the pathophysiology of the two disorders. Additional studies with longitudinal 
designs, particularly to determine the longitudinal protein profiles from those who are initially diagnosed with MDD but develop hypomanic/manic symptoms later, are needed. Additionally, studies involving a larger sample size with more information on covariates that can influence the proteomic profiles, as well as those including validation designs, are warranted.

\section{Supplementary information}

Supplementary information accompanies this paper at https://doi.org/10. 1186/s12888-020-02540-0.

Additional file 1. List of 268 proteins subjected to statistical analysis. (Protein IDs and majority protein IDs).

Additional file 2. Major protein IDs and full protein IDs of the differentially-expressed proteins. (Protein IDs and majority protein IDs).

Additional file 3. IPA Canonical Pathway and IPA Diseases \& Functions.

\section{Abbreviations}

MDD: Major depressive disorder; BD: Bipolar disorder; LC-MS/MS: Liquid chromatography-tandem mass spectrometry; HCD: Higher-energy collisional dissociation; FDR: False discovery rate; DDA: Data-dependent acquisition; DEP: Differentially expressed protein; RAB7A: Ras-related protein Rab-7a; ROCK2: Rho-associated protein kinase 2; XPO7: Exportin-7; LXR: Liver X receptor; RXR: Retinoic acid receptor

\section{Acknowledgements}

Not applicable.

\section{Authors' contributions}

Drafting of the manuscript: S.J.R. and D.H. Analysis of serum samples: H.S., H.K.2 and D.H. Study design: H.K.1, J. L, T.Y.L, M. K, S.H.K. Y.M.A, J.S.K, D. H, K.H. Data collection: Y. L, K. L, Y.M.A, K.H. All authors read and approved the final manuscript

\section{Funding}

This study was supported by a grant of the Korea Health Technology R\&D Project through the Korea Health Industry Development Institute (KHIDI), funded by the Ministry of Health \& Welfare, Republic of Korea (grant number: HI17C0870), and a grant from the Ministry of Science, ICT, and Future Planning, Republic of Korea (grant number: NRF-2019M3C7A1030625). The funding body had no involvement in study design planning, data collection, analysis, interpretation of data in writing the manuscript.

\section{Availability of data and materials}

The datasets used and/or analysed during the current study are available from the corresponding author on reasonable request.

\section{Ethics approval and consent to participate}

Written informed consent was obtained from all individuals. Both the individuals and parents/guardians informed consent was obtained for those under the age of 18. The study protocol was approved by the Institutional Review Board of Seoul National University Hospital (IRB No. 1704-075-846) and was conducted in accordance with the Declaration of Helsinki.

\section{Consent for publication}

Not applicable.

\section{Competing interests}

The authors declare that they have no competing interests.

\section{Author details}

'Department of Neuropsychiatry, Seoul National University Hospital, Seoul, Republic of Korea. ${ }^{2}$ Department of Psychiatry, Seoul National University College of Medicine, Seoul, Republic of Korea. ${ }^{3}$ Proteomics Core Facility, Biomedical Research Institute, Seoul National University Hospital, Seoul, Republic of Korea. ${ }^{4}$ Department of Psychiatry, Inha University Hospital,
Incheon, Republic of Korea. ${ }^{5}$ Department of Pathology, Seoul National University College of Medicine, Seoul, Republic of Korea. ${ }^{6}$ Institute of Human Behavioral Medicine, Seoul National University Medical Research Center, Seoul, Republic of Korea. ${ }^{7}$ Department of Neuropsychiatry, Pusan National University Yangsan Hospital, Yangsan, Republic of Korea.

Received: 2 May 2019 Accepted: 10 March 2020

Published online: 03 April 2020

\section{References}

1. Shin C, Kim Y, Park S, Yoon S, Ko YH, Kim YK, Kim SH, Jeon SW, Han C. Prevalence and associated factors of depression in general population of Korea: results from the Korea National Health and nutrition examination survey, 2014. J Korean Med Sci. 2017;32(11):1861-9.

2. Grande I, Berk M, Birmaher B, Vieta E. Bipolar disorder. Lancet. 2016; 387(10027):1561-72

3. Lim D, Lee WK, Park H. Disability-adjusted life years (DALYs) for mental and substance use disorders in the Korean burden of disease study 2012. J Korean Med Sci. 2016;31(Suppl 2):S191-9.

4. Kim W, Jang SY, Chun SY, Lee TH, Han KT, Park EC. Mortality in schizophrenia and other psychoses: data from the South Korea National Health Insurance Cohort, 2002-2013. J Korean Med Sci. 2017;32(5):835-42.

5. Nunez NA, Comai S, Dumitrescu E, Ghabrash MF, Tabaka J, Saint-Laurent M, Vida S, Kolivakis T, Fielding A, Low N, et al. Psychopathological and sociodemographic features in treatment-resistant unipolar depression versus bipolar depression: a comparative study. BMC Psychiatry. 2018;18(1): 68.

6. Ghaemi SN, Boiman EE, Goodwin FK. Diagnosing bipolar disorder and the effect of antidepressants: a naturalistic study. J Clin Psychiatry. 2000;61(10): 804-8.

7. Fritz K, Russell AMT, Allwang C, Kuiper S, Lampe L, Malhi GS. Is a delay in the diagnosis of bipolar disorder inevitable? Bipolar Disord. 2017;19(5):396400.

8. Yoon W, Shon SH, Hong Y, Joo YH, Lee JS. Antidepressant prescription patterns in bipolar disorder: a Nationwide, register-based study in Korea. J Korean Med Sci. 2018;33(46):e290.

9. Pacchiarotti I, Bond DJ, Baldessarini RJ, Nolen WA, Grunze H, Licht RW, Post RM, Berk M, Goodwin GM, Sachs GS, et al. The International Society for Bipolar Disorders (ISBD) task force report on antidepressant use in bipolar disorders. Am J Psychiatry. 2013;170(11):1249-62.

10. Breen MS, Stein DJ, Baldwin DS. Systematic review of blood transcriptome profiling in neuropsychiatric disorders: guidelines for biomarker discovery. Hum Psychopharmacol. 2016;31(5):373-81.

11. Hoehe MR, Morris-Rosendahl DJ. The role of genetics and genomics in clinical psychiatry. Dialogues Clin Neurosci. 2018;20(3):169-77.

12. Comes AL, Papiol S, Mueller T, Geyer PE, Mann M, Schulze TG. Proteomics for blood biomarker exploration of severe mental illness: pitfalls of the past and potential for the future. Transl Psychiatry. 2018:8(1):160.

13. Domenici $E$, Muglia P. The search for peripheral disease markers in psychiatry by genomic and proteomic approaches. Expert Opin Med Diagn. 2007;1(2):235-51.

14. Preece RL, Han SYS, Bahn S. Proteomic approaches to identify blood-based biomarkers for depression and bipolar disorders. Expert Rev Proteomics. 2018;15(4):325-40

15. Bot M, Chan MK, Jansen R, Lamers F, Vogelzangs N, Steiner J, Leweke FM, Rothermundt M, Cooper J, Bahn S, et al. Serum proteomic profiling of major depressive disorder. Transl Psychiatry. 2015:5:e599.

16. Haenisch F, Alsaif M, Guest PC, Rahmoune H, Dickerson F, Yolken R, Bahn S. Multiplex immunoassay analysis of plasma shows prominent upregulation of growth factor activity pathways linked to GSK3beta signaling in bipolar patients. J Affect Disord. 2014;156:139-43.

17. Frye MA, Nassan M, Jenkins GD, Kung S, Veldic M, Palmer BA, Feeder SE, Tye SJ, Choi DS, Biernacka JM. Feasibility of investigating differential proteomic expression in depression: implications for biomarker development in mood disorders. Transl Psychiatry. 2015;5:e689.

18. Alsaif M, Guest PC, Schwarz E, Reif A, Kittel-Schneider S, Spain M, Rahmoune $\mathrm{H}, \mathrm{Bahn} \mathrm{S}$. Analysis of serum and plasma identifies differences in molecular coverage, measurement variability, and candidate biomarker selection. Proteomics Clin Appl. 2012;6(5-6):297-303.

19. Ren J, Zhao G, Sun $X$, Liu H, Jiang $P$, Chen J, Wu Z, Peng D, Fang Y, Zhang C. Identification of plasma biomarkers for distinguishing bipolar depression 
from major depressive disorder by iTRAQ-coupled LC-MS/MS and bioinformatics analysis. Psychoneuroendocrinology. 2017;86:17-24

20. Chen J, Huang C, Song Y, Shi H, Wu D, Yang Y, Rao C, Liao L, Wu Y, Tang J, et al. Comparative proteomic analysis of plasma from bipolar depression and depressive disorder: identification of proteins associated with immune regulatory. Protein Cell. 2015;6(12):908-11.

21. Hamilton M. Development of a rating scale for primary depressive illness. Br J Soc Clin Psychol. 1967;6(4):278-96

22. Geyer PE, Kulak NA, Pichler G, Holdt LM, Teupser D, Mann M. Plasma proteome profiling to assess human health and disease. Cell Syst. 2016;2(3): 185-95.

23. Han D, Jin J, Woo J, Min H, Kim Y. Proteomic analysis of mouse astrocytes and their secretome by a combination of FASP and StageTip-based, high pH, reversed-phase fractionation. Proteomics. 2014;14(13-14):1604-9.

24. Woo J, Han D, Park J, Kim SJ, Kim Y. In-depth characterization of the secretome of mouse CNS cell lines by LC-MS/MS without prefractionation. Proteomics. 2015;15(21):3617-22.

25. Nagaraj N, Kulak NA, Cox J, Neuhauser N, Mayr K, Hoerning O, Vorm O, Mann M. System-wide perturbation analysis with nearly complete coverage of the yeast proteome by single-shot ultra HPLC runs on a bench top Orbitrap. Mol Cell Proteomics. 2012;11(3):M111.013722.

26. Lee H, Kim K, Woo J, Park J, Kim H, Lee KE, Kim H, Kim Y, Moon KC, Kim JY, et al. Quantitative proteomic analysis identifies AHNAK (neuroblast differentiation-associated protein AHNAK) as a novel candidate biomarker for bladder Urothelial carcinoma diagnosis by liquid-based cytology. Mol Cell Proteomics. 2018;17(9):1788-802.

27. Tyanova S, Temu T, Cox J. The MaxQuant computational platform for mass spectrometry-based shotgun proteomics. Nat Protoc. 2016;11(12):2301-19.

28. Cox J, Neuhauser N, Michalski A, Scheltema RA, Olsen JV, Mann M. Andromeda: a peptide search engine integrated into the MaxQuant environment. J Proteome Res. 2011;10(4):1794-805

29. Tyanova S, Temu T, Sinitcyn P, Carlson A, Hein MY, Geiger T, Mann M, Cox J. The Perseus computational platform for comprehensive analysis of (prote) omics data. Nat Methods. 2016;13(9):731-40

30. Kramer A, Green J, Pollard J Jr, Tugendreich S. Causal analysis approaches in ingenuity pathway analysis. Bioinformatics. 2014;30(4):523-30.

31. Rodriguez L, Mohamed NV, Desjardins A, Lippe R, Fon EA, Leclerc N. Rab7A regulates tau secretion. J Neurochem. 2017;141(4):592-605.

32. Ma G, Liu M, Du K, Zhong X, Gong S, Jiao L, Wei M. Differential expression of mRNAs in the brain tissues of patients with Alzheimer's disease based on GEO expression profile and its clinical significance. Biomed Res Int. 2019; 2019:8179145

33. Armstrong A, Mattsson N, Appelqvist H, Janefjord C, Sandin L, Agholme L, Olsson B, Svensson S, Blennow K, Zetterberg H, et al. Lysosomal network proteins as potential novel CSF biomarkers for Alzheimer's disease. NeuroMolecular Med. 2014;16(1):150-60.

34. Zhurov V, Stead JD, Merali Z, Palkovits M, Faludi G, Schild-Poulter C, Anisman $\mathrm{H}$, Poulter MO. Molecular pathway reconstruction and analysis of disturbed gene expression in depressed individuals who died by suicide. PLoS One. 2012;7(10):e47581

35. Mateus D, Marini ES, Progida C, Bakke O. Rab7a modulates ER stress and ER morphology. Biochim Biophys Acta Mol Cell Res. 2018;1865(5):781-93.

36. Gold PW, Licinio J, Pavlatou MG. Pathological parainflammation and endoplasmic reticulum stress in depression: potential translational targets through the CNS insulin, klotho and PPAR-gamma systems. Mol Psychiatry. 2013;18(2):154-65.

37. Pfaffenseller B, Wollenhaupt-Aguiar B, Fries GR, Colpo GD, Burque RK, Bristot G, Ferrari P, Cereser KM, Rosa AR, Klamt F, et al. Impaired endoplasmic reticulum stress response in bipolar disorder: cellular evidence of illness progression. Int J Neuropsychopharmacol. 2014;17(9):1453-63.

38. Lizaso A, Tan KT, Lee YH. Beta-adrenergic receptor-stimulated lipolysis requires the RAB7-mediated autolysosomal lipid degradation. Autophagy. 2013;9(8):1228-43.

39. Mondal AC, Fatima M. Direct and indirect evidences of BDNF and NGF as key modulators in depression: role of antidepressants treatment. Int J Neurosci. 2019;129(3):283-96.

40. Segoviano-Mendoza M, Cardenas-de la Cruz M, Salas-Pacheco J, VazquezAlaniz F, La Llave-Leon O, Castellanos-Juarez F, Mendez-Hernandez J, Barraza-Salas M, Miranda-Morales E, Arias-Carrion O, et al. Hypocholesterolemia is an independent risk factor for depression disorder and suicide attempt in Northern Mexican population. BMC Psychiatry. 2018; 18(1):7.

41. Chong CM, Ai N, Lee SM. ROCK in CNS: different roles of isoforms and therapeutic target for neurodegenerative disorders. Curr Drug Targets. 2017; 18(4):455-62.

42. Nakagawa O, Fujisawa K, Ishizaki T, Saito Y, Nakao K, Narumiya S. ROCK-I and ROCK-II, two isoforms of rho-associated coiled-coil forming protein serine/ threonine kinase in mice. FEBS Lett. 1996;392(2):189-93.

43. Olivier JD, Akerud H, Skalkidou A, Kaihola H, Sundstrom-Poromaa I. The effects of antenatal depression and antidepressant treatment on placental gene expression. Front Cell Neurosci. 2015;8:465

44. Lech K, Ackermann K, Revell VL, Lao O, Skene DJ, Kayser M. Dissecting daily and circadian expression rhythms of clock-controlled genes in human blood. J Biol Rhythm. 2016;31(1):68-81.

45. Saito T, Hirano M, Ide T, Ichiki T, Koibuchi N, Sunagawa K, Hirano K. Pivotal role of rho-associated kinase 2 in generating the intrinsic circadian rhythm of vascular contractility. Circulation. 2013;127(1):104-14.

46. Krane-Gartiser K, Vaaler AE, Fasmer OB, Sorensen K, Morken G, Scott J. Variability of activity patterns across mood disorders and time of day. BMC Psychiatry. 2017;17(1):404.

47. Johnson C, Drgon T, Liu QR, Walther D, Edenberg H, Rice J, Foroud T, Uhl GR. Pooled association genome scanning for alcohol dependence using 104,268 SNPs: validation and use to identify alcoholism vulnerability loci in unrelated individuals from the collaborative study on the genetics of alcoholism. Am J Med Genet B Neuropsychiatr Genet. 2006;141b(8):844-53.

48. Aksu M, Pleiner T, Karaca S, Kappert C, Dehne HJ, Seibel K, Urlaub H, Bohnsack MT, Gorlich D. Xpo7 is a broad-spectrum exportin and a nuclear import receptor. J Cell Biol. 2018;217(7):2329-40.

49. Lydall GJ, Bass NJ, McQuillin A, Lawrence J, Anjorin A, Kandaswamy R, Pereira A, Guerrini I, Curtis D, Vine AE, et al. Confirmation of prior evidence of genetic susceptibility to alcoholism in a genome-wide association study of comorbid alcoholism and bipolar disorder. Psychiatr Genet. 2011;21(6): 294-306.

50. Edwards PA, Kennedy MA, Mak PA. LXRs; oxysterol-activated nuclear receptors that regulate genes controlling lipid homeostasis. Vasc Pharmacol. 2002;38(4):249-56

51. Yang C, Zhou C, Li J, Chen Z, Shi H, Yang W, Qin Y, Lu L, Zhao L, Fang L, et al. Quantitative proteomic study of the plasma reveals acute phase response and LXR/RXR and FXR/RXR activation in the chronic unpredictable mild stress mouse model of depression. Mol Med Rep. 2018;17(1):93-102.

52. Bhattacharya A, Derecki NC, Lovenberg TW, Drevets WC. Role of neuroimmunological factors in the pathophysiology of mood disorders. Psychopharmacology. 2016;233(9):1623-36.

53. Wu Y, Tang J, Zhou C, Zhao L, Chen J, Zeng L, Rao C, Shi H, Liao L, Liang Z, et al. Quantitative proteomics analysis of the liver reveals immune regulation and lipid metabolism dysregulation in a mouse model of depression. Behav Brain Res. 2016;311:330-9.

54. Hamdani N, Bengoufa D, Godin O, Doukhan R, Le Guen E, Daban-Huard C, Bennabi M, Delavest M, Lepine JP, Boukouaci W, et al. Immunoglobulin subclass distribution in bipolar disorder and schizophrenia: potential relationship with latent toxoplasma Gondii infection. BMC Psychiatry. 2018; 18(1):239.

\section{Publisher's Note}

Springer Nature remains neutral with regard to jurisdictional claims in published maps and institutional affiliations.

Ready to submit your research? Choose BMC and benefit from:

- fast, convenient online submission

- thorough peer review by experienced researchers in your field

- rapid publication on acceptance

- support for research data, including large and complex data types

- gold Open Access which fosters wider collaboration and increased citations

- maximum visibility for your research: over $100 \mathrm{M}$ website views per year

At BMC, research is always in progress.

Learn more biomedcentral.com/submissions 